\title{
Nota sobre as categorias "gênero" $e$ "sexualidade" e os povos indígenas*
}

Cecilia McCallum**

Se a antropologia se preocupa com a possível violência epistemológica desencadeada pelo uso de categorias universalizantes (como gênero) para falar de práticas e formas de pensamento indígenas, o mesmo não pode ser dito sobre as preocupações indígenas para com suas próprias categorias, pragmática ou discursivamente elaboradas no sentido oposto. Para a grande maioria, por exemplo, a norma é que os homens se engajem diretamente com o mundo exterior dos "brancos", dentro da lógica do que se costuma chamar da divisão sexual do trabalho, fortemente presente nas mais diversas organizações sociais indígenas. Para uma analise antropológica, tratar desse fenômeno em termos de uma categoria analítica de "gênero", devidamente controlada etnograficamente, rende bastante.

Gênero e sexualidade fazem parte dos modos de conceber $e$ constituir (ou não) as relações sociais com seres marcados pela alteridade. As formas do uso de sexualidade são múltiplas. Para os Huni Kuin (Kaxinawá), com quem convivi nos anos 1980, é raro casar com estranhos; preferem namorar e casar com primos da categoria correta, ou seja, da metade exogâmica oposta. As moças se interessam pelos rapazes desde o início da puberdade e os pais procuram incentivar casamentos apropriados logo que começam a fazer sexo para não engravidarem enquanto solteiras. Mas,

\footnotetext{
Recebido para publicação em 20 de setembro de 2013, aceito em 5 de novembro de 2013. Agradeço a todos os colegas na lista de SALSA que enviaram sugestões e referências sobre os temas tratados aqui

** Professora Adjunta, Departamento de Antropologia, Universidade Federal da Bahia; Pesquisadora, MUSA-Programa de Estudos em Gênero e Saúde, ISC/UFBA. Cecilia.McCallum@uol.com.br
}

cadernos pagu (41), julho-dezembro de 2013:53-61. 
Nota sobre as categorias "gênero" e "sexualidade" e os povos indígenas

embora os Huni Kuin prefiram a endogamia, a sexualidade é o idioma preferido para pensar nas relações com aqueles estranhos tidos como aliados potenciais, que são tratados com piadas carregadas de insinuações sexuais. Dirigem-se aos Nawa (estranhos) masculinos com o termo txai - primo-cunhado - assim abrindo o caminho para relações jocosas.

Uma vez batizada com um nome verdadeiro, o que me inseriu em relações de afinidade e parentesco como todos os demais assim batizados, aprendi rapidamente a brincar com os meus próprios "primos-cunhados". "Cante para ele", as mulheres mais velhas insistiam "Diga 'Seu pênis parece com o pescoço de um jabuti'! Vá, Filha, cante....". E os meus "primos", sorrindo, retrucavam com a mesma moeda, para o deleite de todos.

O fascínio com sexualidades outras se faz notar. Uma noite ouvi uma história sobre homens vestidos de mulheres vistos em Pucallpa - chamados "maricones", que faziam sexo com outros homens, que suscitava risos e certa incredulidade. De fato, era mais comum ouvir contar sobre sexo entre animais e humanos do que entre pessoas do mesmo sexo, já que muitos mitos incluem episódios desse gênero. No entanto, as personagens, como o homem-anta ou a mulher-anaconda, eram descritas como "gente", ou seja, da perspectiva dos seus amantes humanos tinham corpos humanos. Encontros sexuais com "outros" ocorrem em carne e osso também, não só em estados alterados de percepção ou na imaginação - quando na cidade, por exemplo, alguns homens visitam bordéis ou arranjam amantes. A pornografia é outra fonte de interesse masculino, seja na internet ou impressa. Uma vez um líder voltou da cidade com uma revista de histórias em quadrinhos pornográfica que foi examinada com muitas risadas por todos. As crianças acabaram rasgando as páginas repletas de imagens e durante algumas semanas, inúmeros fragmentos, com fotos explícitos dos Nawa praticando estranhos atos sexuais, flutuaram livremente na aldeia, já sem maior interesse para os moradores. 
Enquadrar a temática de sexualidades indígenas numa dicotomia que opõe modernidade à tradição representa uma violência epistemológica maior do que aquela que porventura resulta do uso de uma categoria analítica como gênero. A expressão "povo tradicional" pouco faz jus aos modos de ser indígenas, não obstante a visão hegemônica veiculada nos meios de comunicação latino-americanos e fixada no imaginário popular. Pessoas nascidas e criadas nos ambientes sociais denominados indígenas aprendem formas de pensar $e$ fazer abertas à inovação e à criatividade. Não se concebem como acorrentados por uma "cultura" objetificada e estagnada no tempo, para cuja constatação existe farta documentação na literatura antropológica das ultimas décadas. Muitos pensadores e políticos indígenas aprenderam os termos-chaves dos discursos dos povos colonizadores, dentro dos contextos diversos em que vivem, dos quais lançam mão frente à necessidade ou ao desejo da interlocução com os povos vizinhos. Nos embates e diálogos com Nawa, os conceitos e categorias importados são adaptados e transformados, e novos conceitos emergem. As pessoas indígenas não se encontram reduzidas por supostas "culturas tradicionais" a formas rígidas de ação e pensamento. Tampouco estão em vias de simples perda de cultura ou de extinção étnica, por serem expostas às formas $e$ práticas hegemônicas, como a heterossexualidade normativa na marca euro-americana, por mais dramáticas que sejam as situações de vulnerabilidade em que se encontrem. Ao apropriar o próprio conceito de cultura, por exemplo, os Huni Kuin o têm reformulado segundo o seu próprio entendimento e para os seus próprios fins, muitas vezes inovando sobre isso a partir do seu engajamento em processos sociopolíticos contra-hegemônicos, dentro dos quais atuam com imaginação $e$ vigor como principiantes (Weber, 2006).

Faço essas observações no intuito de deixar claro que o velho modelo que imaginava um processo evolutivo ou de degradação a partir de um ponto de partida "tradicional" caracterizado por uma construção social de gênero 
Nota sobre as categorias "gênero" e "sexualidade" e os povos indígenas

etnograficamente particular, que seria acompanhado por formas mais ou menos exóticas de sexualidade, na direção de um suposto arranjo "moderno", imaginado como "ocidental", de fato obscurece em vez de iluminar. Na medida em que uma ideia de "cultura indígena" como um tipo exótico de "cultura tradicional" evoque esse modelo, leva a compreensões fortemente enviesadas das trocas e colaborações entre pessoas criadas dentro de regimes de socialidade historicamente distintas, cujas bases filosóficas e formas de habitar o mundo evidenciam diferenças profundas, mas também pontos de contato.

Os regimes de socialidade indígena se assentam sobre os corpos e os processos corporais, cuja existência e evolução dependem da agência humana e não, como na abordagem ontológica pós-iluminista de maior influência no Brasil, de leis impessoais da "natureza" (Belaunde, 2005; McCallum, 2001). Afirmar isso evidentemente não remete a uma simples inversão da velha fórmula atrás da distinção já desgastada entre sexo e gênero, em que o primeiro diria respeito a uma base biológica e o segundo a uma elaboração cultural. $\mathrm{Na}$ poderosa síntese de Viveiros de Castro (2002, 2013), de grande repercussão na etnologia indígena, o perspectivismo ameríndio instiga modos de viver e pensar pautados na ideia de que os corpos são múltiplos e a cultura única. Ou seja, nessa ontologia, muitos seres se enxergam como humanos e veem o mundo como composto de objetos e seres, conforme as classificações típicas da "cultura" humana, embora nós, a partir de nossos corpos vivos, os enxerguemos como animais, plantas ou espíritos. Quando se fala de gênero e de sexualidade indígenas, portanto, em vez de supor que esses conceitos são fadados a reduzir a discussão à velha fórmula de construção cultural ou social, a partir de uma epistemologia da representação, é necessário seguir a trilha aberta pelos extensos e profundos diálogos dos etnógrafos com as pessoas indígenas com quem dialogam, para nos aproximarmos aos corpos e às imbricações e criações corporais que chamamos de sexualidade e reprodução, da forma mais honesta possível. 
A grande maioria desses trabalhos aborda o gênero na perspectiva da heterossexualidade, sendo a homossexualidade mencionada em alguns poucos casos, sendo alvo de investigação direta apenas nos últimos anos - por exemplo, Bacigalupo (2007), Cancela et al (2010), embora Clastres (1969) tenha escrito sobre o tópico. São poucos os estudos diretos sobre sexualidade entre povos indígenas ${ }^{1}$, embora muitas etnografias publicadas contenham informações sobre o tema, algo compreensível dado à naturalidade com que eles normalmente a tratam. Piadas picantes feitas às custas de visitantes, ou cunhados ou cunhadas, mitos contados para adultos e crianças, jogos, danças e cantos rituais falam explicitamente de relações sexuais, constituindo a sexualidade como aspecto possivel ou necessário a relações de alteridade de todos os tipos, seja inter-humano, inter-espécies ou entre humanos e espíritos. Fernandes (2013) faz uma revisão sobre o campo, se inspirando em críticas do conceito de gênero e da noção de terceiro gênero do movimento queer para tratar da homossexualidade, a partir de uma perspectiva teórica desenvolvida por intelectuais indígenas norte-americanas - two spirit theory. No entanto, Fernandes não explora o tema a partir dos insights e debates na rica literatura etnográfica sobre corporalidade e socialidade entre os povos indígenas da América do Sul. É um trabalho ainda a ser feito.

Uma discussão bibliográfica comparativa do que essa literatura etnológica diz sobre gênero e sexualidade seria o primeiro passo para aprofundar nosso entendimento nessa área (o mesmo poderia ser dito sobre o amor hetero e homossexual entre os povos indígenas). Nesta nota apenas pude indicar algumas das obras clássicas sobre os temas e mostrar a importância deles para compreender as antropologias e sociologias indígenas. Nas referências bibliográficas incluo indicações de colegas, enviadas à lista de SALSA (Society for the Study of Lowland South America), tanto

\footnotetext{
${ }^{1}$ Rose-France de Farias Panet escreveu uma tese sobre sexualidade Canela (2010) complementando o trabalho dos Crocker (ver Crocker e Crocker 2004, 2009).
} 
Nota sobre as categorias "gênero" e "sexualidade" e os povos indígenas

de artigos e livros reconhecidos, quanto de alguns estudos mais recentes, no intuito de abrir o caminho para futura investigação.

\section{Referências bibliográficas}

ALES, Catherine. Yanomami, l'ire et le désir. Paris, Editions Karthala, 2006.

. Pourquoi les Yanowamï ont-ils des filles?. In: GodELIER, M. et PANNOFF, M. Le corps humain. Corps conçu, supplicié, cannibalisé, possédé. Paris, CNRS Editions, 2009, pp.287-318.

. Art corporel, savoir et engendrement chez les Yanomami. In: Boetsch, G.; Cheve, D. \& Claudot-Hawad, H. (dirs.) Décors des corps. Paris, CNRS Editions, 2010, pp.331-341.

BACIGALUPO, Ana Mariella. Rethinking Identity and Feminism: Contributions of Mapuche Women and Machi from Southern Chile. Hypatia: A journal of feminist philosophy 18(2), Wiley-Blackwell, 2003, pp.32-57.

- The Struggle for Machi Masculinities: Colonial Politics of Gender, Sexuality and Power in Chile. Ethnohistory 51(3), Duke University Press, 2004a, pp.489-533.

. The Mapuche Man Who Became a Woman Shaman: Selfhood, Gender Transgression, and Competing Cultural Norms. American Ethnologist 31(3), Wiley-Blackwell, 2004b, pp.440-457.

Shamans of the Foye Tree: Gender, Power, and Healing among the Chilean Mapuche. Austin, University of Texas Press, 2007.

. Las Mujeres Machi en el Siglo XX-XI: ¿Personificación de la Tradición o Desafío a las Normas de Género?. In: STUVEN, A. M. e FERMANDOIS, J. (eds.) Historia de las Mujeres en Chile Siglos XX-XI. Santiago, Chile, Editorial Taurus, 2013.

BELAUNDE OlsCHEWSKI, L. E. Viviendo Bien: Género y Fertilidad entre los Airo-Pai de la Amazonia Peruana. Lima, CAAAP / BCRP, 2001.

. El recuerdo de Luna: género, sangre y memoria entre los pueblos amazónicos. Lima, Universidad Nacional Mayor de San Marcos, 2005. 
CAncela, F. L. A. da S. \& MAChADO, Almires. Caminhos de uma pesquisa acerca da sexualidade em aldeias indígenas no Mato Grosso do Sul. Revista de Antropologia, 53 (1), São Paulo, EdUSP, 2010, pp.199-235.

Clastres, P. The Bow and the Basket. In: Society Against the State. Social Science Information, 8(3), Sage journals, 1969,pp.145-162.

. Misfortune of the savage warrior. In: Archaeology of Violence. The MIT Press, Cambridge, 1994.

Crocker, W. H. and Crocker, J. The Canela: Kinship, Ritual, and Sex in an Amazonian Tribe. Case Studies. In: SPINDLER, George (series ed.) Cultural Anthropology. Belmont, CA, Thomson/Wadsworth, 2004.

. Os Canelas: Parentesco, Ritual e Sexo em uma tribo da chapada Maranhense. Série Monografias, A. Freire, 2009. [Tradução: (1) Família DePaula/Filgueiras, (2) Julio Melatti e (3) Helena de Barros]

FERNANDES, E. R. Ativismo homossexual indígena e decolonialidade: da teoria queer às críticas two-spirit. $37^{\circ}$ Encontro Anual da ANPOCS, SPG 16 Sexualidade e gênero: espaço, corporalidades e relações de poder, Águas de Lindoia, SP, de 23 a 27 de setembro de 2013.

GRAHAM, L. R. Genders of Xavante ethnographic spectacle: Cultural politics of inclusion and exclusion in Brazil. In: GRAHAM, L. R. e GlenN PenNY, H. (eds.) Performing Indigeneity. University of Nebraska Press, 2014.

Gregor, T. Anxious Pleasures: The sexual lives of an Amazonian People. Chicago, University of Chicago Press, 1985.

JACKSON, J. The meaning and message of symbolic sexual violence in Tukanoan ritual. Anthropological Quarterly 65 (1), Washinton DC, The George Washington University Institute for Ethnographic Research, 1992, pp.1-18.

JUNQUEIRA, C. e MiNDLIN, Betty. Índias e antropólogas; diálogo de Carmen Junqueira e Betty Mindlin. Estudos Avançados 17 (49), São Paulo, EdUSP, 2003, pp.235-251. 
Nota sobre as categorias "gênero" e "sexualidade" e os povos indígenas

KENSINGER, Kenneth. How real people ought to live: the Cashinahua of Eastern Peru. Prospect Heights, Waveland Press, 1995.

LAGROU, E. M. A fluidez da forma: Arte, alteridade e ação em uma sociedade amazônica (Kaxinawá, Acre). Rio de Janeiro, Topbooks, 2007.

LASMAR, Cristiane. De Volta ao Lago de Leite: Gênero e transformação no Alto Rio Negro. São Paulo, Editora UNESP/ISA; Rio de Janeiro, NUTI, 2005.

LIMA, Tânia Stolze. Um peixe olhou para mim: O povo Yudjá e a perspectiva. São Paulo, Editora UNESP/Instituto Socioambiental / NUTI, 2005.

. Por uma cartografia do poder e da diferença nas cosmopolíticas ameríndias. Revista de Antropologia 54(2), São Paulo, EdUSP, 2011, pp.601-646.

LONDONO SULKIN, C. D. People of Substance: An Ethnography of Morality in the Colombian Amazon. University of Toronto Press, 2012.

McCallum, Cecilia. Comendo com Txai, comendo como Txai: A sexualização de relações étnicas na Amazônia contemporânea. Revista de Antropologia 40, São Paulo, EdUSP, 1997, pp.109-147.

. Gender and Sociality in Amazonia: How Real People are Made. Oxford, Berg, 2001.

. Escrito no corpo: gênero, educação e socialidade na Amazônia numa perspectiva Kaxinawá. Revista da FAEEBA, vol. 19, $\mathrm{n}^{\circ}$ 33, Salvador, UNEB, 2010a, pp.87-104. Disponível em: $<$ http://www.ppgeduc.com/revistadafaeeba/anteriores/numero33 >.

. Becoming a Real Woman: Alterity and the Embodiment of Cashinahua Gendered Identity. Tipití, The Journal of the Society for the Anthropology of Lowland South America 7, Digital commons@ Trinity, 2010b, pp.43-66.

RUBENSTEIN, S. L. Fieldwork and the Erotic Economy on the Colonial Frontier. Signs: Journal of Women in Culture and Society, vol. 29, $\mathrm{n}^{\circ}$ 4, 2004, pp.1041-1071.

Seeger, A.; DA MatTA, R. \& Viveiros De Castro, E. A construção da pessoa nas sociedades indígenas brasileiras. In: PACHECO DE OLIVEIRA, 
J. (org.) Sociedades Indígenas \& Indigenismo no Brasil. Rio de Janeiro, UFRJ, Editora Marca Zero, 1987[1979].

SHEPARD, G. Three Days for Weeping: Dreams, Emotions, and Death in the Peruvian Amazon. Medical Anthropology Quarterly 16(2), WileyBlackwell, 2002, pp.200-229. .

SISKIND, J. To Hunt in the Morning, Oxford, Oxford University Press, 1973.

ViveIROS DE CASTRO, E. A Inconstância da Alma Selvagem. Rio de Janeiro, Cosac Naify, 2002.

WEBER, Ingrid. Um copo de cultura: os Huni Kuin (Kaxinawá) do rio Humaitá e a escola. Rio Branco, Edufac, 2006. 